\title{
En-1 and En-2, two mouse genes with sequence homology to the Drosophila engrailed gene: expression during embryogenesis
}

\author{
Alexandra L. Joyner and Gail R. Martin \\ Department of Anatomy, University of California at San Francisco, San Francisco, California 94143 USA
}

Two mouse genes, En-1 and En-2, have sequence homology to the engrailed (en) and invected (inv) genes of Drosophila (Joyner et al. 1985). Partial nucleotide sequence analyses of genomic and cDNA clones show that the homologous sequences can encode a stretch of 107 amino acids, including a centrally located, 60-amino-acid homeo box. Within the homologous regions of the mouse and Drosophila genes, $78(73 \%)$ of the amino acids are identical. Such extensive conservation of sequence outside the homeo box between vertebrate and Drosophila homeo box-containing genes is thus far unique. En-1 and En-2 are expressed during mouse embryogenesis. Transcripts from both genes were detected in RNA samples from teratocarcinoma cells, which serve as in vitro models for the early embryo, and from embryos at 9.5 through 17.5 days of development. For each gene we observed a unique pattern of changes in the number and relative intensities of transcripts detectable during embryonic development. Transcripts from both genes are represented abundantly in RNA extracted from the posterior portion of the fetal brain, and are much less abundant in RNA from other fetal tissues, including the anterior portion of the brain and the spinal cord. The chromosome map positions of En-1 and En-2 were determined by recombinant inbred strain analyses. Unlike their Drosophila counterparts, they are unlinked: $E n-1$ is in the central portion of the mouse chromosome 1 and En-2 is in the proximal portion of mouse chromosome 5 . Both genes map in the vicinity of mutations that are known to cause abnormalities during development.

[Key Words: Homeo box; invected gene; chromosome mapping; developmental mutants]

Received November 3, 1986; accepted November 25, 1986.

Development in multicellular organisms can be viewed as a two-step process. First, a general body plan is established, and subsequently the various components of the basic body plan diversify and specialize. It has not been obvious how to identify or isolate the genes responsible for the control of these processes in vertebrate species. However, the existence of mutations that perturb these processes in Drosophila melanogaster has led to the identification of three groups of genes that control development in that organism: The maternal effect and segmentation genes function to establish a body plan composed of repeating segmental units which are subdivided

1Present address: Division of Molecular and Developmental Biology, Mt. Sinai Hospital Research Institute, Toronto, Canada M5G 1 X5. into anterior and posterior compartments, and the homeotic genes function to provide each segment with a specific identity (Ouweneel 1976; Lewis 1978; Nusslein-Volhard 1979; Kaufman et al. 1980; Nusslein-Volhard and Weischaus 1980). Many of these genes have now been cloned, and a substantial proportion have been found to contain a common 180-bp sequence known as the homeo box (reviewed by Gehring 1985), which is also conserved in the vertebrate genome (McGinnis et al. 1984).

The Drosophila engrailed gene (en) is known to play an important role in segmentation (Lawrence and Morata 1976; Kornberg 1981; Lawrence and Struhl 1982), and genetic analysis has led to the suggestion that en functions as a binary developmental switch to "select" the cells in the posterior compartment (Garcia-Bellido 1975). Consistent with this hypothesis is the dem- 
onstration, by in situ RNA hybridization (Fjose et al. 1985; Ingham et al. 1985; Kornberg et al. 1985; Weir and Kornberg 1985) and antibody localization of the en protein product (DiNardo et al. 1985), that en is expressed only in the cells of the posterior compartments during the early stages of embryonic development. Molecular studies have led to the identification of a gene adjacent to en, now designated invected (inv), which has extensive sequence homology with it (Poole et al. 1985). Sequence comparisons of en and inv cDNA clones (Coleman et al. this issue) have revealed two regions of homology between the genes. One region includes a stretch that encodes 17 contiguous amino acids that are identical in the two genes. This region is separated, by sequences encoding 5 (en) or 26 (inv) nonconserved amino acids, from a second downstream region, which contains a homeo box that is very similar in en and inv, but quite divergent from the homeo boxes found in other Drosophila genes. Additional homologous sequences encoding 31 amino acids are found immediately downstream of the homeo box. In situ RNA hybridization analysis of inv expression in developing Drosophila embryos has shown that, like en, it is expressed selectively in the cells of the posterior compartments /Coleman et al., this issue). These results suggest that the en and inv genes have related functions during embryogenesis. As yet, however, no mutations of inv are known that would suggest its role in development.

In a previous study (Joyner et al. 1985), we attempted to determine whether the Drosophila engrailed gene had been conserved during the evolution of higher vertebrates. Southern blot hybridization analysis revealed two regions of the mouse genome with sequence homology to an en cDNA clone. These regions are designated En-1 and En-2 (previously they were termed Mo-en.1 and Mo-en.2). One of these genomic regions, En-1, was cloned and mapped to mouse chromosome 1. Nucleotide sequence analysis of En-1 genomic DNA revealed that it contains at least part of the conserved coding sequences common to the Drosophila en and inv genes. These include the homeo box and 21 amino acids immediately downstream from it. The studies described here were undertaken in part to determine whether the second region of homology between the Drosophila en and inv genes, $5^{\prime}$ to the homeo box, is also conserved in the En-1 gene, and to determine to what extent the mouse genomic region designated En-2 conserves the sequences common to the two Drosophila genes. To achieve this, we isolated and sequenced En-2 genomic clones and cDNA clones representing embryonic mRNAs encoded by both the En-1 and En-2 genes. Moreover, we have extended our previous studies, showing that En-1 is expressed in cultures of teratocarcinoma cells and in mouse embryos from 9.5 to 17.5 days of gestation, to define the stage-specificity of En-2 RNA expression during embryogenesis. We have also carried out experiments aimed at defining the tissue specificity of En-1 and En-2 in the embryo and at obtaining estimates of the positions of these genes in the mouse linkage map.

\section{Results}

Conservation in En-1 and En-2 of the sequences common to en and inv

Two overlapping En-2 genomic clones, $\lambda$ En-2.1 and $\lambda$ En-2.2, were isolated by screening a mouse genomic DNA library with an En-1 homeo box region probe (see Materials and methods). A partial restriction map of the genomic region represented by these clones is shown in Figure 1a. The same probe was also used to screen a 12.5-day mouse embryo cDNA library /see Materials and methods) for En-1 and En-2 cDNA clones. Eight unique phage were isolated. Restriction enzyme analysis of their inserts demonstrated that three represented one mRNA and five another. Each of the shorter cDNAs appeared to be identical to one end of the longest cDNA in its respective group, and the largest cDNA of each group, 1.2 and $3 \mathrm{~kb}$, respectively, was chosen for further analysis. Hybridization of these cDNAs to Southern blots of cloned En-1 and En-2 genomic DNA indicated that they represent transcripts of the En-1 and En-2 genes, respectively (Fig. la and data not shown). The $1.2-\mathrm{kb}$ cDNA clone was therefore designated $\mathrm{En}-\mathrm{lc}$ and the $3.0-\mathrm{kb}$ cDNA clone En-2c (Fig. 1b).

A comparison of the sequences in the region surrounding the homeo box (Fig. 2a) revealed a remarkable degree of homology between En-1 and En-2. For the genomic sequences, this region of homology includes the nucleotides at positions 59-375 in Figure 2a. Each of these sequences constitutes an open reading frame that contains the homeo box (positions 100-279) and ends with a signal for the termination of protein synthesis. However, $5^{\prime}$ of the homeo box, at a position $41 \mathrm{bp}$ from its start (position 59 in Fig. 2a), the En-1 genomic sequence diverged significantly from that of En-2, and both were found to contain a consensus splice acceptor site (Mount 1982) adjacent to and including the nucleotides at position 59 (sequences not shown). The cDNA sequences of En-1 and En-2 were determined for the region extending $5^{\prime}$ from the SstI site in the homeo box through to the nucleotides at position 1 in Figure 2a. For each gene, the cDNA sequence was found to be identical to that of its corresponding genomic clone up to the consensus splice site and then to diverge. The En-1 and En-2 cDNA sequences $5^{\prime}$ of position 59 were found to be highly homologous to each other and extended the open reading frame containing the homeo box. In the composite cDNA and genomic sequences shown in Figure $2 a, 295$ of 375 nucleotides $(79 \%)$ are identical. The results of preliminary sequencing studies and analysis of cross-hybridization between the cDNA and genomic clones suggest that the sequences following the stop codon in the En-2 transcript constitute an exceptionally long $3^{\prime}$ untranslated region of $\cong 1.5 \mathrm{~kb}$, whereas the corresponding region of the En-1 transcript contains only $\cong 500 \mathrm{bp}$ (see Fig. $1 \mathrm{~b}$ ).

The 124 amino acids that can be encoded by the En-1 and En-2 homeo box regions are shown in comparison with the corresponding sequences of the Drosophila en and inv genes in Figure 2b. Although these four se- 

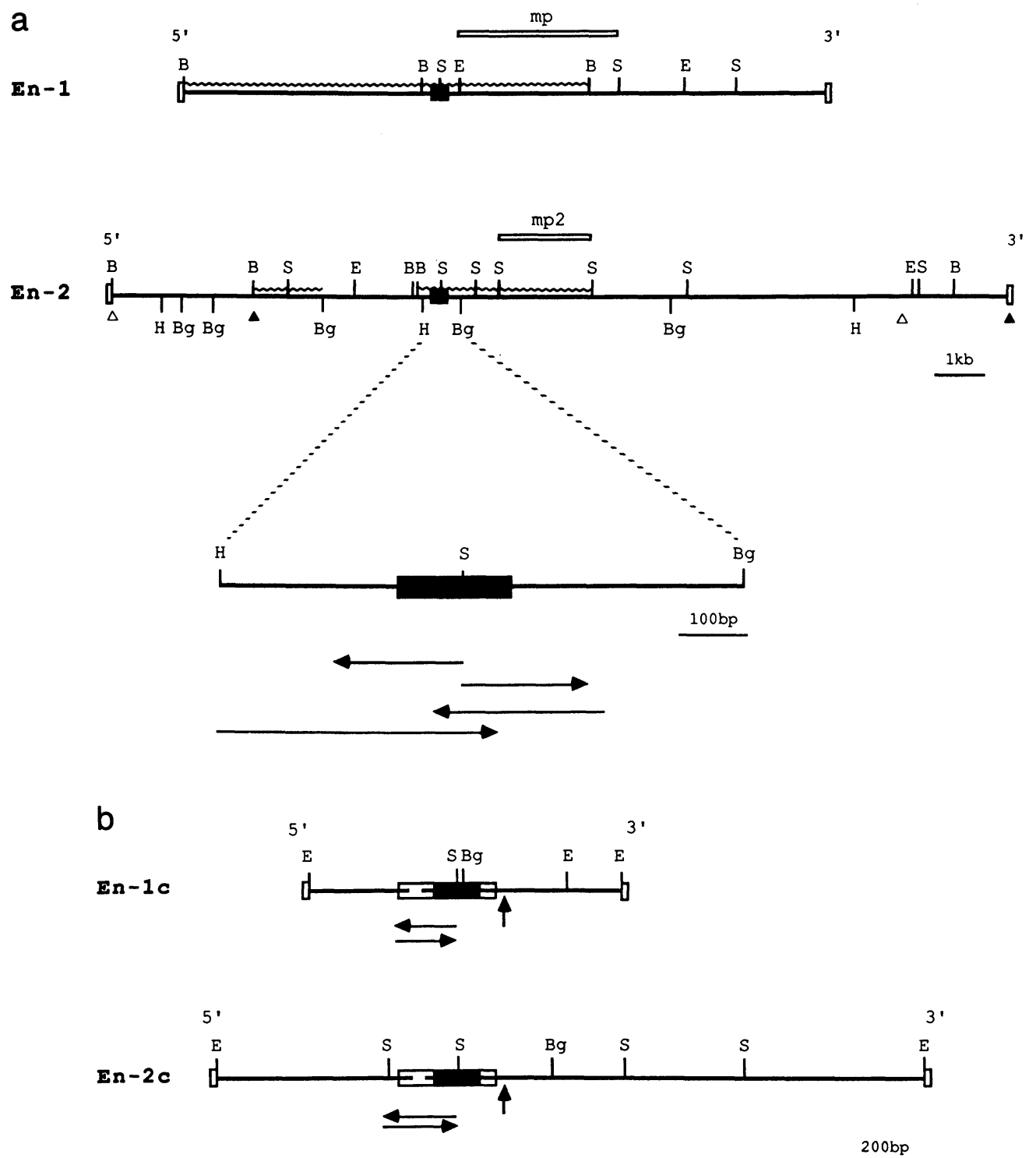

Figure 1. Restriction maps of En-1 and En-2 genomic and cDNA clones. (a) A partial restriction map of the En-1 genomic region, as previously determined by Joyner et al. (1985), is shown in comparison with a partial restriction map of the En-2 genomic region. The open boxes mark the ends of the cloned regions. For En-2, the upper horizontal line represents the total combined length of mouse genomic DNA contained in the $\lambda E n-2.1$ and $\lambda E n-2.2$ clones. The open and filled triangles indicate the lengths of the $\lambda E n-2.1$ and $\lambda$ En-2.2 inserts, respectively. The lower horizontal line is an enlargement of the HindIII-BglII restriction fragment containing the homeo box, which is shown as a filled box. The direction of transcription of En-1 was previously determined using a single-stranded DNA probe to detect the En-1 transcripts in embryo RNA samples (Joyner et al. 1985). The direction of transcription of En-2 was inferred from the sequence of the open reading frame including the homeo box; this is supported by sequencing data showing that the predicted $3^{\prime}$ end of the En-2c cDNA clone contains a poly $(\mathrm{A})^{+}$tail. The open boxes marked mp and mp 2 represent the subcloned fragments used as probes for the mapping studies. For En-1, the wavy lines above the genomic DNA indicate the restriction fragments that hybridize with the 1.2-kb En-1c cDNA clone shown in Fig. 1b; similarly, for En-2 the wavy line indicates those fragments that hybridize with the 3-kb En-2c cDNA clone. (B) BamHI; (H) HindIII; (Bg) BglII; (S) SstI; (E) EcoRI. (b) The horizontal lines indicate the DNA inserts in the $\lambda E n-1 \mathrm{c}$ and $\lambda E n-2 c$ cDNA clones, with the small open boxes indicating the ends of the inserts, which contain synthetic EcoRI sites. The filled boxes represent the homeo box in each clone and the large open boxes surrounding them delineate the extent of the region of homology between En-1 and En-2, as it is presently known from comparison of the DNA sequences that were determined. The space interrupting each horizontal line denotes the position of the splice site $5^{\prime}$ of the homeo box. In each cDNA, the vertical arrow indicates the end of the open reading frame that includes the homeo box. The cDNA regions that were sequenced are shown as horizontal arrows pointing in the direction of sequencing. (E) EcoRI; $(\mathrm{S}) S s t \mathrm{I} ;(\mathrm{Bg}) \mathrm{BgIII}$. 

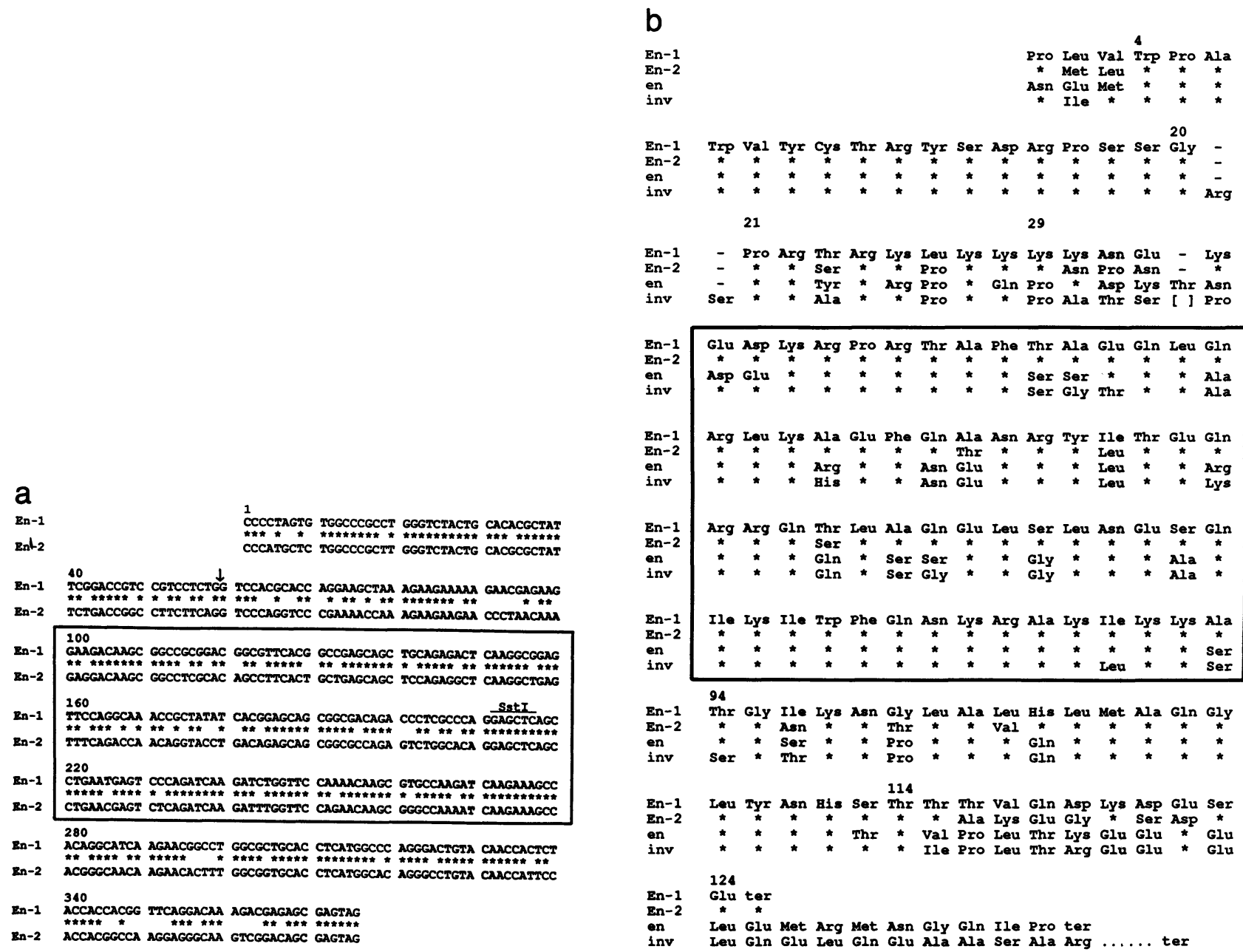

Figure 2. Sequence analysis of the region conserved in En-1 and En-2 and the Drosophila en and inv genes. (a) Composite genomic and cDNA sequences of the regions surrounding the homeo boxes in En-1 and En-2. The direction of transcription is from left to right. For both genes the arrow indicates the boundaries of an intron, and the box delineates the homeo box. The SstI site in the homeo box is indicated. Asterisks denote nucleotides that are identical in En-1 and En-2. The last three nucleotides encode a termination signal for translation of the open reading frame. The sequences of $400 \mathrm{bp}$ of En-1 and En-2 genomic DNA surrounding the SstI site in the homeo box were determined; most of the En-1 genomic DNA sequence shown was previously published (Joyner et al. 1985). The cDNA clones were sequenced from the nucleotides at positions 1-211. For both En-1 and En-2, respectively, the genomic and cDNA sequences were identical from the nucleotides at positions 59 through 211. (b) Translation of the En-1 and En-2 DNA sequences shown in $a$, in comparison with the corresponding amino acid sequences of the Drosophila en and inv genes. The sequences were aligned to achieve the best match. To accomplish this a space, denoted by a dash $(-)$, was left between amino acids that are actually contiguous in En-1 and En-2. In addition, 22 amino acids in the inv sequence, denoted by brackets ([I]), are not shown. The dots represent six amino acids in the inv sequence immediately upstream from the stop codor. The homeo box is delineated by a box. An asterisk denotes amino acids in the En-2, en, and inv sequences that are identical to the amino acid in the corresponding position in the En-1 sequence. The en and inv sequences were determined by Poole et al. (1985) and Coleman et al. (this issue). (en) engrailed; (inv) invected.

quences are not perfectly colinear, they can be aligned by making certain assumptions: en contains one additional amino acid, and inv contains 22 amino acids between positions 32 and 33 in the En-1 and En-2 sequences; in addition, inv contains two amino acids inserted between positions 20 and 21 in the mouse sequences. It is obvious from this comparison that there is a region that is remarkably conserved between the two mouse and two Drosophila genes that extends over most of the sequences shown. The conserved region begins with a stretch of 17 contiguous amino acids that are identical in all four genes (positions numbered 4-20). Each of the four genes contains an intron that interrupts the nucleotide sequence coding for the last of these 17 amino acids (position 20 in Fig. 2b). The first nine of the next 13 amino acids in the sequence /positions numbered 21-29) represent a conserved domain in which seven are identical in En-1 and En-2, and of these seven, four are also conserved in en and six are conserved in inv. The remaining four amino acids in this 
stretch (positions 30-33) represent a region in which the most variation occurs in the four genes; the two Drosophila genes each contain additional amino acids in this region. The next 60 amino acids in the sequence, delineated by a box in Figure $2 \mathrm{~b}$, constitute the homeo box in which 56 of 60 amino acids $(93 \%)$ are identical in the two mouse genes, and 42 of 60 amino acids (70\%) are identical in all four genes. In the two Drosophila genes, but not the mouse genes, the homeo box is interrupted by an intervening sequence. Immediately downstream of the homeo box there is a region (amino acids numbered $94-114)$ in which 18 of 21 amino acids (86\%) are identical in the two mouse genes and 15 of 21 amino acids $(71 \%)$ are identical in all four genes. Although the predicted amino acid sequences of en and inv are homologous for an additional 10 amino acids, these amino acids are not conserved in either mouse gene.

Stage and tissue specificity of En-1 and En-2 during embryogenesis

In our previous study (Joyner et al. 1985) we examined the expression of the En-1 gene by Northern blot hybridization analysis of poly $(\mathrm{A})^{+}$RNA extracted from PSA-1 teratocarcinoma cells, which serve as an in vitro model system for the mouse embryo at the peri-implantation stages of development (3.5-6.5 days of gestation; Martin 1980), and from whole mouse embryos at the mid- and late-gestation stages of development. Using a 150-base single-stranded En-1 homeo box region probe, we detected a relatively low-abundance En-1 transcript in
RNA from undifferentiated teratocarcinoma stem cells. Following differentiation of the PSA-1 cells, an additional, larger En-1 transcript became detectable. Both transcripts were observed in RNA from embryos at 9.5 through 17.5 days of gestation. However, whereas the less abundant, smaller transcript appeared to be expressed at relatively constant levels in all samples tested, the levels of the more abundant, larger transcript decreased late in development. These results were confirmed in the present study using the En-1 cDNA probe (Fig. 3a, and data not shown).

In contrast to the pattern described for En-1, a single 3.7-kb En-2 RNA was readily detected at approximately equivalent levels in all teratocarcinoma samples tested. In samples of poly $(\mathrm{A})^{+}$RNA from embryos, the pattern
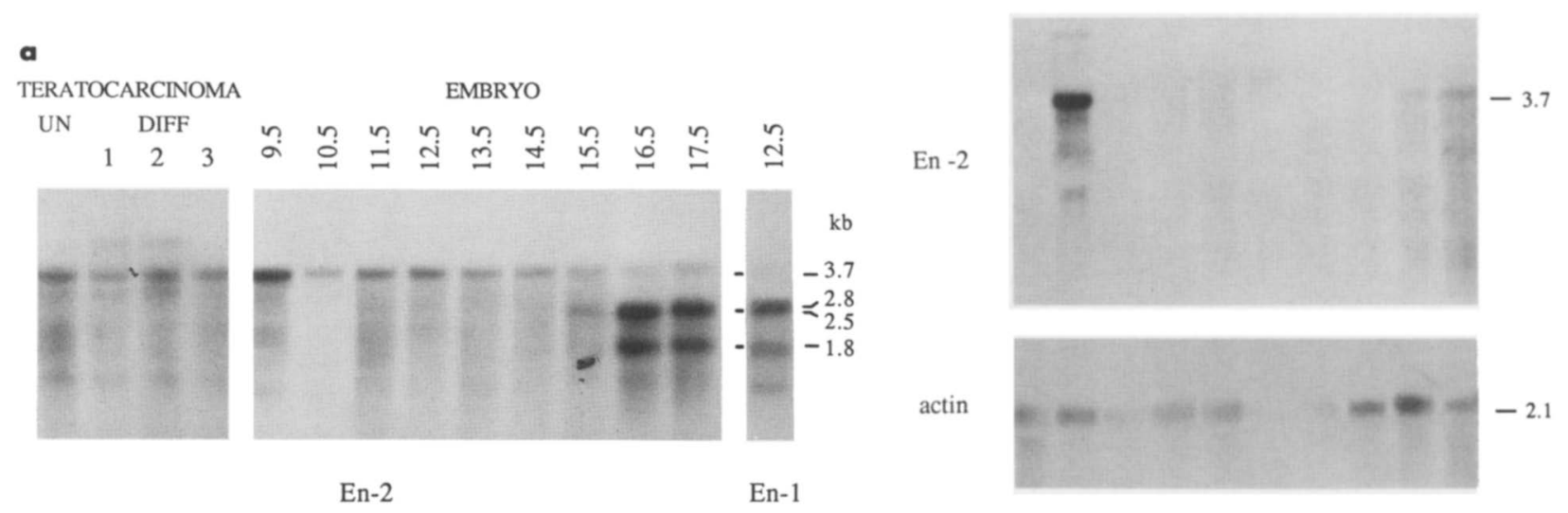

Higure 3. Expression of En-1 and En-2 RNA during mouse embryogenesis. (a) Expression of En-2 in teratocarcinoma cells and mouse embryos at various stages of gestation. A Northern blot of poly $(A)^{+}$RNA $(5 \mu \mathrm{g})$ isolated from PSA-1 teratocarcinoma stem cells maintained in the undifferentiated state (un) and at three stages of differentiation (diff 1, 2,3; see Joyner et al. 1985), and from whole embryos at the days of gestation indicated, was analyzed by hybridization under conditions of high stringency using the En-2c cDNA insert probe. For comparison, the filter was stripped and rehybridized under the same conditions with the En-1c cDNA insert probe; the lane containing the 12.5-day embryo sample is shown on the right. The sizes of the two En-1 transcripts were previously estimated to be 2.0 and $3.1 \mathrm{~kb}$ (Joyner et al. 1985), but are now calculated to be 1.8 and $2.8 \mathrm{~kb}$, respectively. (b) Tissue specificity of En-1 and En-2 expression at midgestation. The tissues indicated were dissected from mouse fetuses at 12.5 days of gestation. The brain was removed from the head and divided into the anterior portion, containing the two frontal lobes, and the posterior portion consisting of midbrain, cerebellum, pons, and medulla; the remainder of the head constituted the "face" sample. The spinal cord sample was free of the spinal column but included the spinal ganglia. The "viscera" sample contained a pool of internal organs, and the "carcass" sample contained what remained of the fetus after the other tissues were removed. In addition, yolk sac and placenta samples were dissected from the conceptuses. A Northern blot of total RNA $(15 \mu \mathrm{g})$ from each tissue was analyzed by reiterative hybridizaton and stripping using the En-1c and En-2c cDNA insert probes, and a probe for $\beta$-actin. 
of En-2 expression was found to be more complex: The 3.7-kb En-2 RNA was detected in all embryo samples tested, but two smaller transcripts, of approximately 2.5 and $1.8 \mathrm{~kb}$ in length, became detectable by 15.5 days and were found at relatively high levels in the samples from embryos at 16.5 and 17.5 days of gestation. The increase in abundance of these two smaller transcripts coincided with a decrease in the abundance of the $3.7-\mathrm{kb}$ transcript (Fig. 3a). In most samples, other very weakly hybridizing transcripts were also detected. The results of rehybridizing the blot shown in Figure $3 a$ with a probe for $\beta$-actin indicated that the apparent peak in abundance of the 3.7-kb En-2 RNA at 9.5 days of gestation was probably an artifact due to differences in the amount of RNA present in each lane (data not shown).

To examine the tissue-specificity of En-1 and En-2 transcripts, conceptuses at 12.5 days of gestation were dissected into seven fetal and two extraembryonic parts and total RNA was extracted from each sample. Northern blot hybridization analysis showed that the 2.8-kb En-1 RNA was most abundant in the sample containing the posterior portion of the brain. This sample consisted primarily of midbrain, but also included cerebellum, pons, and medulla. As shown in Figure $3 \mathrm{~b}$, the 2.8-kb En-1 RNA was approximately three- to fivefold more abundant in the posterior brain sample than in those from the anterior portion of the brain, the spinal cord, face, limbs, or carcass; samples derived from the viscera appeared to be completely negative. Although there were several faint bands of hybridization in the lanes containing RNA from yolk sac and from placenta, neither of these extraembryonic tissue samples contained detectable amounts of the 2.8-kb En-1 RNA. The 1.8-kb En-1 RNA observed in all poly $(\mathrm{A}){ }^{+}$RNA samples from teratocarcinoma cells and embryos was not observed in any of the total RNA samples from fetal tissues, possibly because it is expressed in most tissues at levels too low to detect under the conditions we employed.

The data in Figure $3 \mathrm{~b}$ show that the $3.7-\mathrm{kb}$ En-2 transcript is also abundant in the RNA sample from the posterior portion of the brain and no En-2 RNA is detectable in the other samples. However, upon longer exposure of such autoradiographs, the $3.7-\mathrm{kb}$ En-2 transcript was detectable in all samples except that from the anterior brain (not shown). Abundant expression of both En-1 and $E n-2$ in the posterior portion of the brain continues after development, since the 2.8-kb En-1 and 3.7-kb En-2 transcripts were also readily detectable in total RNA samples from this portion of the brain of 17.5-day fetuses and of newborn mice (data not shown); in the other tissues tested (see Materials and Methods), the $2.8-\mathrm{kb}$ En-1 RNA was detectable only in spinal cord, at relatively low abundance, whereas En-2 RNA was not detectable. Moreover, the 2.8-kb En-1 and 3.7-kb En-2 transcripts were also detected in poly $(\mathrm{A})+$ RNA from adult brain (data not shown). The two smaller En-2 transcripts were not detected in any of the tissue samples analyzed from 17.5-day fetuses, or from newborn or adult mice.

\section{Genetic mapping of the En-1 and En-2 loci}

Previous studies employing a panel of hamster-mouse somatic cell hybrids showed that En-1 maps to mouse chromosome 1 (Joyner et al. 1985). To determine its map position, we carried out a recombinant inbred (RI) strain analysis (Taylor 1981), using a set of $26 \mathrm{RI}$ strains derived from $\mathrm{C} 57 \mathrm{BL} / 6$ (B) and $\mathrm{DBA}$ (D) mice $(\mathrm{B} \times \mathrm{D}$ strains). Such analysis is feasible because there is a restriction fragment length polymorphism (RFLP) between En-1 sequences in the B and D strains (see Materials and methods). The strain distribution pattern (SDP) of the En-1 alleles was determined by hybridizing the En-1 mapping probe ( $\mathrm{mp}$; see Fig. 1a) to Southern blots of TaqI digests of genomic DNA from each of $26 \mathrm{~B} \times \mathrm{D} \mathrm{RI}$ strains. Table 1 shows this SDP in comparison with SDPs for the Pep-3 and Sas-1 loci on mouse chromosome 1: 2 of $26 \mathrm{~B} \times \mathrm{D}$ RI strains are recombinant between En-1 and Pep-3, and 3 of 26 strains are recombinant between En-1 and Sas-1. Using the method of Silver (1985) for estimating confidence intervals for linkage estimates based on RI strain analysis, these results place En-1 3.5 cM proximal to Pep-3 $195 \%$ confidence intervals of $1.2-18.3 \mathrm{cM})$. These results are consistent with the preliminary results of a recombinational analysis which show that En-1 is approximately $7.5 \mathrm{cM}$ proximal to Ren-1,2 (G.R. Martin and A.L. Joyner, unpubl.) and the finding of Buchberg et al. (1986), which showed that En-1 is $8 \mathrm{cM}$ proximal to Pep-3.

A similar type of RI strain analysis was carried out to determine the map position of the En-2 locus. By hybridizing the En-2 mapping probe (mp2; see Fig. 1a) to Southern blots of MspI digests of genomic DNA, the SDP of En-2 alleles was determined in $12 \mathrm{RI}$ strains derived from $\mathrm{C} 57 \mathrm{BL} / 6$ and $\mathrm{C} 3 \mathrm{H}(\mathrm{H})$ mice $(\mathrm{B} \times \mathrm{H}$ strains $)$ and 7 RI strains derived from BALB/c (C) and C57BL/6 mice $(\mathrm{C} \times \mathrm{B}$ strains). The data indicate that $E n-2$ is closely linked to the Emv-1 locus on chromosome 5 . Only 1 of $19 \mathrm{RI}$ strains tested is recombinant between $E n-2$ and $E m v-1$ (Table 1). These results indicate that the En-2 locus lies within $1.4 \mathrm{cM}$ of $E m v-1$ (95\% confidence interval of $0.03-10.7 \mathrm{cM})$. Preliminary results of a recombinational analysis confirm that En-2 maps to mouse chromosome 5 (G.R. Martin and A.L. Joyner, unpubl.). The genetic maps shown in Figure 4 depict the regions surrounding En-1 on chromosome 1 and En-2 on chromosome 5 .

\section{Discussion}

The mouse has two genes, En-1 and En-2, that have conserved the majority of the sequences that are homologous in the two Drosophila genes, engrailed and invected. The region of homology, containing a centrally located homeo box, can code for 107 amino acids (positions 4-29 and 34-114; Fig. 2b), of which 78 (73\%) are identical in all four genes. No other regions of significant homology have been found between the two Drosophila genes (Coleman et al., this issue), and relevant data for the two mouse genes are not yet available. The 
Table 1. Segregation of En-1 with linked markers in $B \times D$ RI strains and segregation of En-2 with linked markers in $B \times H$ and $C \times B R I$ strains

\begin{tabular}{|c|c|c|c|c|c|c|c|c|c|c|c|c|c|c|c|c|c|c|c|c|c|c|c|c|c|}
\hline \multirow[b]{2}{*}{ Locus } & \multicolumn{25}{|c|}{ B $\times$ D RI strain ${ }^{a}$} \\
\hline & 1 & 2 & 5 & 6 & 8 & 9 & 112 & 13 & 14 & 15 & 16 & 18 & 19 & 20 & 21 & 22 & 23 & 24 & 25 & 27 & 28 & 29 & 30 & 31 & 32 \\
\hline En-1 & B & B & $\mathrm{D}$ & $\mathrm{D}$ & B & B & B & $\mathrm{D}$ & B & $\mathrm{D}$ & $\begin{array}{l}\mathrm{D} \\
\mathrm{X}\end{array}$ & $\begin{array}{l}\mathrm{D} \\
\mathrm{X}\end{array}$ & B & $\mathrm{D}$ & B & B & $\mathrm{D}$ & $\mathrm{D}$ & B & $\mathrm{D}$ & $\mathrm{D}$ & $\mathrm{D}$ & $\mathrm{D}$ & B & $\mathrm{D}$ \\
\hline Pep-3 & B & B & $\mathrm{D}$ & $\mathrm{D}$ & B & B & B & $\mathrm{D}$ & B & $\begin{array}{l}\mathrm{D} \\
\mathrm{X}\end{array}$ & B & B & B & $\mathrm{D}$ & B & B & $\mathrm{D}$ & $\mathrm{D}$ & B & $\mathrm{D}$ & $\mathrm{D}$ & $\mathrm{D}$ & $\mathrm{D}$ & B & $\mathrm{D}$ \\
\hline \multirow[t]{2}{*}{ Sas-1 } & B & B & $\mathrm{D}$ & $\mathrm{D}$ & B & B & B & $\mathrm{D}$ & B & B & B & B & B & $\mathrm{D}$ & B & B & $\mathrm{D}$ & $\mathrm{D}$ & B & $\mathrm{D}$ & $\mathrm{D}$ & $\mathrm{D}$ & $\mathrm{D}$ & B & $\mathrm{D}$ \\
\hline & \multicolumn{13}{|c|}{$\mathrm{B} \times$ H RI strain ${ }^{\mathrm{b}}$} & & & & & & \multicolumn{7}{|c|}{$\mathrm{C} \times \mathrm{B}$ RI strain ${ }^{\mathrm{b}}$} \\
\hline Locus & 2 & & 3 & 4 & 6 & 7 & 8 & 9 & 10 & 11 & 12 & 14 & 19 & & & & Locus & & $\mathrm{D}$ & $\mathrm{E}$ & G & $\mathrm{H}$ & I & $J$ & $\mathrm{~K}$ \\
\hline En-2 & $\mathrm{H}$ & & $\mathrm{H}$ & B & $\mathrm{H}$ & B & $\mathrm{H}$ & $\mathrm{H}$ & B & B & $\mathrm{H}$ & B & $\mathrm{H}$ & & & & En-2 & & B & $\mathrm{C}$ & B & $\mathrm{C}$ & $\mathrm{C}$ & $\begin{array}{l}C \\
X\end{array}$ & $\mathrm{C}$ \\
\hline$E m v-1$ & $\mathrm{H}$ & & $\mathrm{H}$ & B & $\mathrm{H}$ & B & $\mathrm{H}$ & $\mathrm{H}$ & B & B & $\mathrm{H}$ & B & $\mathrm{H}$ & & & & $E m v-1$ & & B & $\mathrm{C}$ & B & $\mathrm{C}$ & $\mathrm{C}$ & B & $\mathrm{C}$ \\
\hline
\end{tabular}

${ }^{a}$ The letters B and D represent the alleles inherited from progenitor strains C57BL/6J and DBA/2J, respectively. The $\mathrm{X}$ indicates crossover regions. En-1 alleles were typed with the mp probe as described in the text. The SDP for Pep-3 was determined by Wilson et al. (1978) and for Sas-1 by Rosenstreich et al. (1978).

b The letters $\mathrm{B}, \mathrm{H}$, and $\mathrm{C}$ represent the alleles inherited from progenitor strains C57BL/6J, C3H/HeJ, and BALB/c, respectively. The X indicates crossover regions. En-2 alleles were typed with the mp-2 probe as described in the text. The SDP for Emv-1 in the B $\times \mathrm{H}$ RI strains was determined by Jenkins et al. (1982) and in the C $\times$ B RI strains by N. Jenkins and N. Copeland (pers. comm.).

conserved sequences represent a carboxy-terminal protein domain with a molecular mass of approximately 12,000 daltons. The existence of such extensive homology suggests that the conserved domain in the products of all four genes performs a similar biochemical function. Although this function may be related to that of other homeo box-containing genes, it is likely to have some unique features specified by the conserved sequences outside of the homeo box. Such conserved sequences have thus far not been found in any other homeo box-containing genes in Drosophila or vertebrate species.

Although the two mouse genes might be the homologs of the Drosophila engrailed and invected genes with respect to their specific biochemical functions, it remains to be determined whether En-1 and En-2 play some role in the control of embryogenesis in mammals that is in any way analogous to the developmental functions of their counterparts in Drosophila. Our studies establish that both genes are expressed in PSA-1 teratocarcinoma cells maintained in the undifferentiated state and at three different stages of differentiation. Such undifferentiated cells are thought to be equivalent in many respects to the inner cell mass (ICM) cells of the preimplantation mouse blastocyst (3.5-4.5 days of gestation), and the differentiating cultures at stages 1,2 , and 3 appear to represent or have features in common with mouse embryos at stages prior to $14.5-6.5$ days of gestation), during (6.5-8.5 days), and after (8.5-10.5 days) gastrulation, respectively (Martin and Evans 1975a,b; Martin et al. 1977). Thus, the data imply that both genes are expressed early in embryogenesis, during periods when fundamental cell lineage decisions are being made and when the basic embryo body plan is being established. The finding that later in development both En-1 and En-2 are expressed most abundantly in the posterior portion of the brain suggests that both genes have some function in the development of the central nervous system. Expression of both engrailed and invected has also been detected in the central nervous system of developing Drosophila embryos (Ingham et al. 1985; Weir and Kornberg 1985; Coleman et al., this issue). Although it is an attractive idea that there are similarities in the

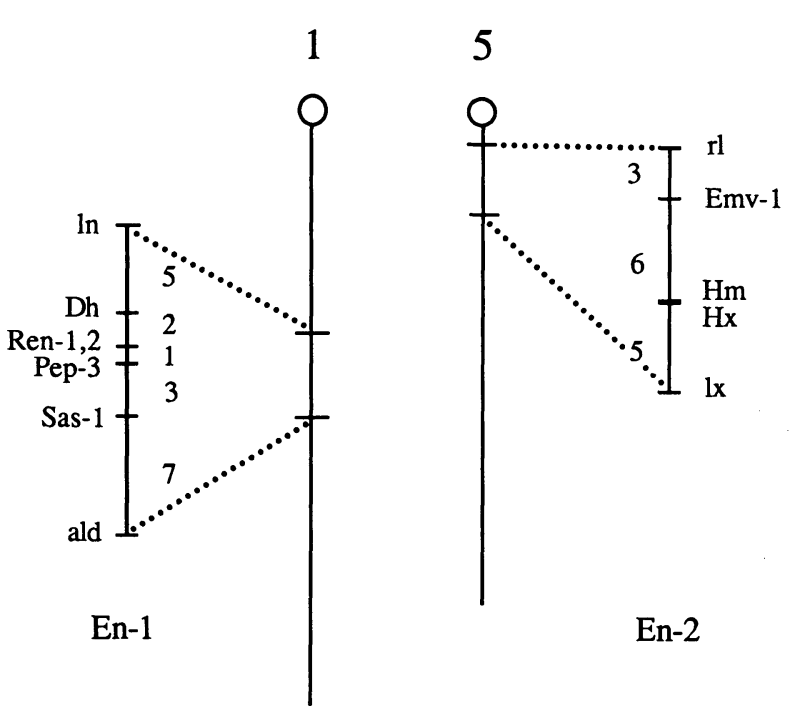

Figure 4. Chromosome maps of the En-1 and En-2 regions. The long vertical lines marked 1 and 5 represent mouse chromosomes 1 and 5, respectively. The open circles indicate the centromeres. The shorter vertical lines represent the region of each chromosome in which En-1 or En-2 is located, and the linkage positions of the mouse genes or markers that have been mapped to these regions are indicated (from Mouse News Letter 1985). 
developmental functions of the mouse and Drosophila genes, at present this is highly speculative. Some insight into this question may be gained from in situ RNA hybridization and protein localization studies of En-1 and En-2 products on sections of mouse embryos, which will serve to define the spatial distribution and cell type specificity of the expression of En-1 and En-2 during mouse embryogenesis.

The data reported here show that En-1 and En-2 are unlinked, whereas the engrailed and invected genes are adjacent to each other in the Drosophila genome /Coleman et al., this issue). Thus, any functional significance in the close linkage of the Drosophila genes has not been conserved in the evolution of the mammalian engrailedlike genes. Both En-1 and En-2 map in the vicinity of mutations that are known to cause developmental abnormalities (Green 1981). En-1 on chromosome 1 is in the vicinity of Dominant hemimelia and En-2 on chromosome 5 is in the vicinity of a pair of genes, Hemimelic extra toes $(\mathrm{Hx})$ and Hammertoe $(\mathrm{Hm})$, which may be allelic since they have never been separated by recombination. It is interesting to note, but perhaps coincidental, that the $D h, H x$, and $H m$ genes all cause similar types of abnormalities in skeletal development. En-2 also maps in the vicinity of reeler ( $r 1)$, a recessive mutation that causes a reduction in the size of the cerebellum with consequent effects on motor activity. Recombination studies to determine whether any of these genes might represent mutant alleles of either En-1 or En-2 are in progess. The identification of an extant mutant allele(s) of one or both of these mouse engrailed-like genes would greatly facilitate the analysis of their function in mammalian development.

\section{Materials and methods}

All experimental procedures were carried out according to the methods described by Maniatis et al. (1982), unless otherwise specified.

\section{DNA probes}

All probes except the En-1 homeo box region probe were radiolabeled to a specific activity of at least $2 \times 10^{8} \mathrm{cpm} / \mu \mathrm{g}$, using a nick-translation kit (Bethesda Research Laboratories). The En-1 homeo box region probe that was used for screening genomic and cDNA libraries was a single-stranded DNA probe derived from an M13 clone, as described previously (a-s probe; Joyner et al. 1985). It consisted of the approximately 150 nucleotides immediately 3 ' to the SstI site in the En-1 homeo box.

The cDNA probes used in the Northern blot hybridization analysis were as follows: the 1-kb EcoRI fragment of the $\lambda \mathrm{En}-\mathrm{lc}$ clone that contains the homeo box, and the entire 3-kb EcoRI insert of the $\lambda \mathrm{En}-2 \mathrm{c}$ clone (see Fig. 1b).

The probes used for the linkage analysis were the En-1 mapping probe $(\mathrm{mp})$, a 3.6-kb EcoRI-SstI subclone of the Mo-en.1 genomic clone (Joyner et al. 1985), and the En-2 mapping probe (mp2), a 2-kb SstI fragment of $\lambda$ En-2.2 (see Fig. 1a). The mp2 fragment was subcloned into the SstI site of the plasmid SP65. The $\mathrm{mp}$ probe hybridizes to fragments of 3.5 and $3.3 \mathrm{~kb}$ in TaqI-digested C57BL/6 genomic DNA and fragments of 4.4 and $3.3 \mathrm{~kb}$ in TaqI digests of DBA/2J DNA. The mp2 probe hybridizes to fragments of 1.5 and $1.3 \mathrm{~kb}$ in MspI digests of genomic DNA from C57BL/6 (B) mice and to a fragment of $2.8 \mathrm{~kb}$ in MspI digests of genomic DNA from $\mathrm{C} 3 \mathrm{H}(\mathrm{H})$ and $\mathrm{BALB} / \mathrm{C}(\mathrm{C})$ mice.

The chicken $\beta$-actin probe was kindly provided by Dr. D. Cleveland (Cleveland et al. 1980).

\section{Isolation of genomic and cDNA clones}

A recombinant $\lambda$ EMBL3A library containing 12 - to $20-\mathrm{kb}$ fragments of genomic DNA, derived from $\mathrm{C} 3 \mathrm{H}$ strain mice, which had been partially digested with Sau3A, was kindly provided by Drs. J. Vogel and R. Goodenow (Department of Genetics, University of California, Berkeley). Approximately 600,000 recombinant phage were screened with the En-1 homeo box region probe under conditions of moderate stringency (see below), and one of the phage obtained was found by restriction analysis to contain the En-1 genomic fragments that were previously isolated. The other two clones represent the En-2 genomic region, as described in the Results.

A $\lambda$ gt 10 cDNA library was constructed according to the procedure of Huynh et al. (1985), and was kindly provided by Dr. Craig Hauser (Department of Biochemistry, University of California, Berkeley). It contains EcoRI cDNA inserts derived from poly $(\mathrm{A})^{+}$RNA extracted from C3H mouse embryos at 12.5 days of gestation. Four phage that carry DNA inserts homologous to the En-1 homeo box region probe were obtained by screening an aliquot of the library that contained 500,000 unique phage. Four additional unique phage were obtained by screening a similar number of phage from another aliquot of the same library following its amplification.

The replica nitrocellulose filters were hybridized for $16 \mathrm{hr}$ at $64^{\circ} \mathrm{C}$ in $5 \times$ SSC, $10 \times$ Denhart's solution, $0.1 \%$ SDS, $0.1 \%$ sodium pyrophosphate, and $15 \%$ deionized formamide. The filters were washed once for $30 \mathrm{~min}$ in $2 \times \mathrm{SSC}, 0.1 \% \mathrm{SDS}$ and twice for $20 \mathrm{~min}$ each in $0.2 \times \mathrm{SSC}, 0.1 \% \mathrm{SDS}$ at $50^{\circ} \mathrm{C}$.

\section{Southern blot hybridization analysis}

Recombinant $\lambda$ phage DNAs $(1 \mu \mathrm{g})$ or total genomic DNAs (10 $\mu \mathrm{g}$ ) isolated from mouse tissues were cleaved with restriction endonucleases, electrophoretically fractionated in $1 \%$ agarose, and transferred to GeneScreen (New England Nuclear) in $10 \times$ SSC. Subsequent to transfer, the nylon filters were exposed to UV light according to the methods of Church and Gilbert (1984). The filters were hybridized at $65^{\circ} \mathrm{C}$ using the following "moderate hybridization conditions": $1 \%$ bovine serum albumin, $0.5 \mathrm{M} \mathrm{NaPO}_{4}$ (pH 7.2), $1 \mathrm{~mm}$ EDTA, 7\% SDS, and 15\% formamide. The filters were washed twice for $20 \mathrm{~min}$ in $2 \times$ SSC, $1 \%$ SDS and once for $30 \mathrm{~min}$ in $0.2 \times$ SSC, $0.1 \%$ SDS at $50^{\circ} \mathrm{C}$. Genomic DNA isolated from RI strain mice was purchased from the Jackson Laboratory (Bar Harbor, Maine).

\section{Nucleotide sequence analysis}

All DNA sequences were obtained by the dideoxynucleotide chain termination technique (Sanger et al. 1977) using the universal 15-mer primer (Pharmacia) or using appropriate synthetic oligonucleotide primers. The $\lambda E n-2.2$ genomic fragments or En-1c and En-2c cDNA fragments for sequencing were cloned into M13 vectors (Messing 1983; Pharmacia) and the recombinant phages to be sequenced were identified by hybridizing replica filters of bacterial host cells (JM101) that had been transfected with the appropriate ligation mixtures to a radioactively labeled En-1 homeo box region probe. DNA for sequencing was then isolated from cross-hybridizing phages (Sanger et al. 1980). All sequences shown were determined by independently sequencing both strands. For each M13 clone, only the length of DNA that was sequenced is indicated in Figure 1. 


\section{Northern blot hybridization analysis}

All procedures were similar to those previously described by Joyner et al. (1985). Mouse embryos at various stages of gestation were obtained by mating random-bred ICR animals (Simenson Laboratories, Gilroy, California). The day on which the vaginal plug was detected was considered 0.5 day of gestation. Embryos at the designated stages were dissected from the implantation site and separated from the extraembryonic membranes. Total cellular RNA was isolated from the following samples using the guanidinium thiocynate/ $\mathrm{CsCl}_{2}$ method of Chirgwin et al. (1979) with some minor modifications: PSA-1 cells cultured under the conditions described by Martin et al. (1977); pools of whole mouse embryos at various times of gestation (see text); tissues dissected from conceptuses at 12.5 days of gestation (see text); anterior and posterior portions of the brain, the spinal cord, heart and lungs, liver, and other viscera from fetuses at 17.5 days of gestation; anterior and posterior portions of the brain, the spinal cord, and the liver from newborn mice; the brain from adult mice. Poly $(\mathrm{A}){ }^{+}$RNA was selected from total RNA isolated from whole embryos, adult brain or PSA-1 cells by oligo(dT)-cellulose column chromatography. RNA was fractionated by gel electrophoresis, transferred to GeneScreen nylon membranes and hybridized under conditions of "high stringency" as described by Joyner et al. (1985).

\section{Acknowledgments}

The authors would like to thank Ms. Andrea Wilson, Mr. Michael Richman, and Bern Philip for technical assistance, and Drs. T. Kornberg, K. Coleman, and S. Poole for access to unpublished data, helpful discussion, and critical review of the manuscript. We are also grateful to our laboratory colleagues, Drs. G. Church, M. Frohman, S. Mansour, and K. Downs for helpful discussions and critical readings of the manuscript. This work was supported by funds from National Institutes of Health grant HD-20959. A.L.J. was supported by a postdoctoral fellowship from the Medical Research Council of Canada.

\section{Note}

Sequence data described in this paper have been submitted to the EMBL/GenBank Data Libraries under the accession numbers Y00201 for En-1 and Y00203 for En-2.

\section{References}

Buchberg, A.M., B.A. Taylor, N.A. Jenkins, and N.G. Copeland. 1986. Chromosomal localization of $E m v-16$ and $E m v-17$, the two closely linked ecotropic proviruses of RF/J mice. $J$. Virol. 60: 1175-1178.

Chirgwin, J.M., A.E. Przybyla, R.J. MacDonald, and W.J. Rutter. 1979. Isolation of biologically active ribonucleic acid from sources enriched in ribonuclease. Biochemistry 18: 52945299.

Church, G.M. and W. Gilbert. 1984. Genomic sequencing. Proc. Natl. Acad. Sci. 81: 1991-1995.

Cleveland, D.W., M.A. Lopata, R.J. MacDonald, N.J. Cowan, W.J. Rutter, and M.W. Kirschner. 1980. Number and evolutionary conservation of a $\alpha$ - and $\beta$-tubulin and cytoplasmic $\beta$ - and $\gamma$-actin genes using specific cloned cDNA probes. Cell 20: $95-100$.

Coleman, K.G., S.J. Poole, M. Weir, W.C. Soeller, and T. Kornberg. 1987. The invected gene of Drosophila: Sequence anal- ysis and expression studies reveal a close kinship to the engrailed gene. Genes Dev. 1: 19-28.

DiNardo, S., J.M. Kuner, J. Theis, and P.H. O'Farrell. 1985. Development of embryonic pattern in $D$. melanogaster as revealed by accumulation of the nuclear engrailed protein. Cell 43: 56-69.

Fjose, A., W.J. McGinnis, and W.J. Gehring. 1985. Isolation of a homeo box-containing gene from the engrailed region of Drosophila and the spatial distribution of its transcripts. Nature 313: 284-289.

Garcia-Bellido, A. 1975. Genetic control of wing disc development in Drosophila. In Cell patterning, Ciba Foundation Symposium 29, new series, pp. 161-182. Elsevier, Amsterdam.

Gehring, W. 1985. The homeo box: A key to the understanding of development? Cell 40: 3-5.

Green, M.C., ed. 1981. Genetic variants and strains of the laboratory mouse. Gustav Fischer Verlag, Stuttgart.

Huynh, T.V., R.A. Young, and R.W. Davis. 1985. Constructing and screening cDNA libraries in $\lambda g t 10$ and $\lambda g t 11$. In DNA cloning (ed. D.M. Glover), vol. 1, pp. 49-78. IRL Press, Oxford and Washington, D.C.

Ingham, P., A. Martinez-Arias, P. Lawrence, and K. Howard. 1985. Expression of engrailed in the parasegment of Drosophila. Nature 317: 634-636.

Jenkins, N.A., N.G. Copeland, B.A. Taylor, H.G. Bedigan, and B.K. Lee. 1982. Ecotropic murine leukemia virus DNA content of normal and lymphomatous tissues of $\mathrm{BXH}-2$ recombinant inbred mice. I. Virol. 42: 379-388.

Joyner, A.L., T. Kornberg, K. Coleman, D. Cox, and G.R. Martin. 1985. Expression during embryogenesis of a mouse gene with sequence homology to the Drosophila engrailed gene. Cell 43: 29-37.

Kaufman, T.C., R. Lewis, and B. Wakimoto. 1980. Cytogenetic analysis of chromosome 3 in Drosophila melanogaster: The homoeotic gene complex in polytene chromosome interval 84A-B. Genetics 94: 115-133.

Kornberg, T. 1981. Engrailed: A gene controlling compartment and segment formation in Drosophila. Proc. Natl. Acad. Sci. 78: $1095-1099$.

Kornberg, T., I. Siden, P. O'Farrell, and M. Simon. 1985. The engrailed locus of Drosophila: In situ localization of transcripts reveals compartment-specific expression. Cell 40: 45-53.

Lawrence, P.A. and G. Morata. 1976. Compartments in the wing of Drosophila: A study in the engrailed gene. Dev. Biol. 50: 321-337.

Lawrence, P.A. and G. Struhl. 1982. Further studies of the engrailed phenotype in Drosophila. EMBO I. 1: 827-833.

Lewis, E.B. 1978. A gene complex controlling segmentation in Drosophila. Nature 276: 565-570.

Maniatis, T., E.F. Fritsch, and J. Sambrook. 1982. Molecular cloning: A laboratory manual. Cold Spring Harbor Laboratory, Cold Spring Harbor, New York.

Martin, G.R. 1980. Teratocarcinomas and mammalian embyrogenesis. Science 209: 768-776.

Martin, G.R. and M.J. Evans. 1975a. Differentiation of clonal lines of teratocarcinoma cells: Formation of embryoid bodies in vitro. Proc. Natl. Acad. Sci. 72: 1441-1445.

- 1975b. Multiple differentiation of clonal teratocarcinoma stem cells following embryoid body formation in vitro. Cell 6: 467-474.

Martin, G.R., L.M. Wiley, and I. Damjanov. 1977. The development of cystic embryoid bodies in vitro from clonal teratocarcinoma stem cells. Dev. Biol. 61: 230-244.

McGinnis, W., R.L. Garber, J. Wirz, A. Kuroiwa, and W.J. 
Gehring. 1984. A homologous protein-coding sequence in Drosophila homeotic genes and its conservation in other metazoans. Cell 37: 403-408.

Messing, J. 1983. New M13 vectors for cloning. Methods Enzymol. 101: 20-78.

Mount, S. 1982. A catalogue of splice junction sequences. $\mathrm{Nu}$ cleic Acids Res. 10: 459-471.

Mouse News Letter. July 1985. 73: 7.

Nüsslein-Volhard, C. 1979. Maternal effect mutations that alter the spatial coordinates of the embryo of Drosophila melanogaster. In Determinants of spatial organization (ed. S. Subtelny and I.R. Konigsberg), pp. 185-211. Academic Press, New York.

Nüsslein-Volhard, C. and E. Weischaus. 1980. Mutations affecting segment number and polarity in Drosophila. Nature 287: 795-801.

Ouweneel, W.J. 1976. Developmental genetics of homeosis. Adv. Genet. 18: 179-248.

Poole, S.J., L.M. Kauvar, B. Drees, and T. Kornberg. 1985. The engrailed locus of Drosophila: Structural analysis of an embryonic transcript. Cell 40: 37-43.

Rosenstreich, D.L., M.G. Groves, H.A. Hoffman, and B.A. Taylor. 1978. Location of the Sas-1 locus on mouse chromosome 1. Immunogenetics 7: 313-320.

Sanger, F., S. Nicklen, and A.R. Coulson. 1977. DNA sequencing with chain-terminating inhibitors. Proc. Natl. Acad. Sci. 74: 5463-5467.

Sanger, F., A.R. Coulson, B.G. Barrell, A.J.H. Smith, and B.A. Roe. 1980. Cloning in single-stranded bacteriophage as an aid to rapid DNA sequencing. J. Mol. Biol. 143: 161-178.

Silver, J. 1985. Confidence limits for estimates of gene linkage based on analysis of recombinant inbred strains. $J$. Hered. 76: $436-440$.

Taylor, B.A. 1981. Recombinant inbred strains. In Genetic variants and strains of the laboratory mouse (ed. M. Green), pp. 397-398. Gustav Fischer Verlag, Stuttgart.

Weir, M. and T. Kornberg. 1985. Patterns of engrailed and fushi tarazu transcripts reveal novel intermediate stages of Drosophila segmentation. Nature 318: 433-439.

Wilson, C.M., E.G. Erdos, J.D. Wilson, and B.A. Taylor. 1978. Location on chromosome 1 of RNR, a gene that regulates renin in the mouse. Proc. Natl. Acad. Sci. 75: 5623-5626. 


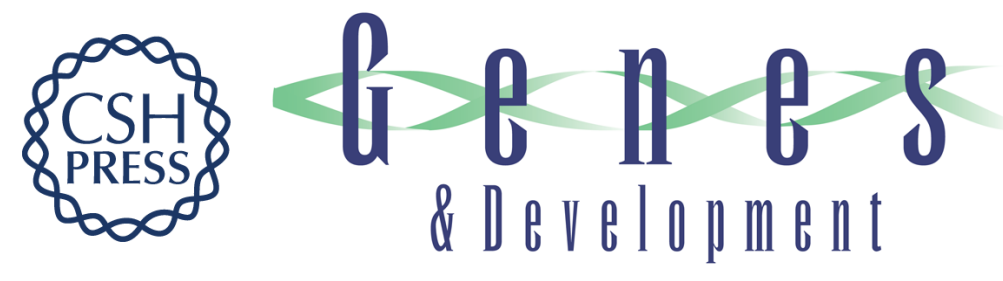

\section{En-1 and En-2, two mouse genes with sequence homology to the Drosophila engrailed gene: expression during embryogenesis.}

A L Joyner and G R Martin

Genes Dev. 1987, 1:

Access the most recent version at doi:10.1101/gad.1.1.29

References This article cites 34 articles, 9 of which can be accessed free at: http://genesdev.cshlp.org/content/1/1/29.full.html\#ref-list-1

License

Email Alerting

Receive free email alerts when new articles cite this article - sign up in the box at the top Service right corner of the article or click here.

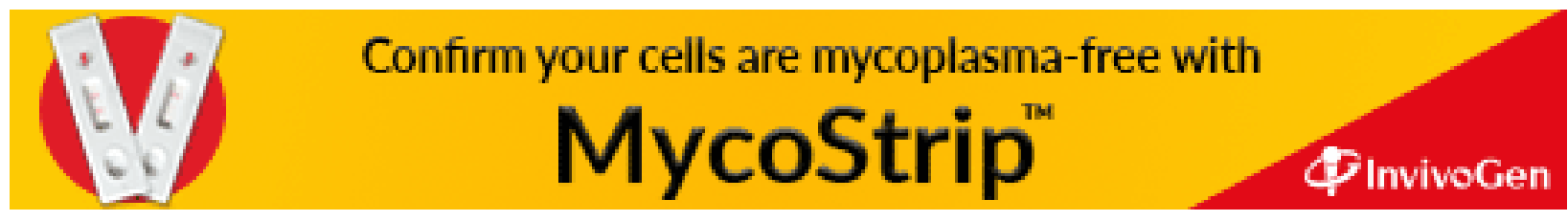

